ENCYCLOPEDDE Encyclopédie berbère

BERBERE

$2 \mid 1985$

2 | Ad - Ağuh-n-Tahlé

\title{
Adrar de Mauritanie
}

(Adyay Tmar)

G. Camps

\section{OpenEdition}

Journals

Édition électronique

URL : http://journals.openedition.org/encyclopedieberbere/865

DOI : $10.4000 /$ encyclopedieberbere.865

ISSN : 2262-7197

\section{Éditeur}

Peeters Publishers

\section{Édition imprimée}

Date de publication : 1 novembre 1985

Pagination : 153-156

ISBN : 2-85744-209-2

ISSN : $1015-7344$

\section{Référence électronique}

G. Camps, «Adrar de Mauritanie », Encyclopédie berbère [En ligne], 2 | 1985, document A65, mis en ligne le 01 décembre 2012, consulté le 25 septembre 2020. URL : http://journals.openedition.org/ encyclopedieberbere/865; DOI : https://doi.org/10.4000/encyclopedieberbere.865

Ce document a été généré automatiquement le 25 septembre 2020.

(c) Tous droits réservés 


\section{Adrar de Mauritanie}

\section{(Adyay Tmar)}

\section{G. Camps}

Cette vaste région de Mauritanie dont la surface est estimée à $215000 \mathrm{~km}^{2}$ est appelée aussi Adrar occidental. Les principaux centres sont Atar, Chin-guetti (Šingēti) et Ouadane (Wadan). L'Adrar mauritanien occupe la partie méridionale de ce que les géologues ont appelé la « dorsale des Regueibat ». Il est constitué de plateaux bordés de longues falaises de grès et de conglomérats primaires reposant sur le socle antécambrien. Il s'agit des restes d'un immense synclinal primaire qui, vers l'ouest, s'étendait jusqu'à Taoudeni. L'Adrar enserre la double dépression du Makteir au nord et du vaste erg Ouaran au sud-est. Il domine au sud et à l'est, par une côte de grés ordovicien, les pays bas de l'Aouker et du Hodh. Vers l'ouest, une côte semblable donne sur la dépression de l'Amsaga. 


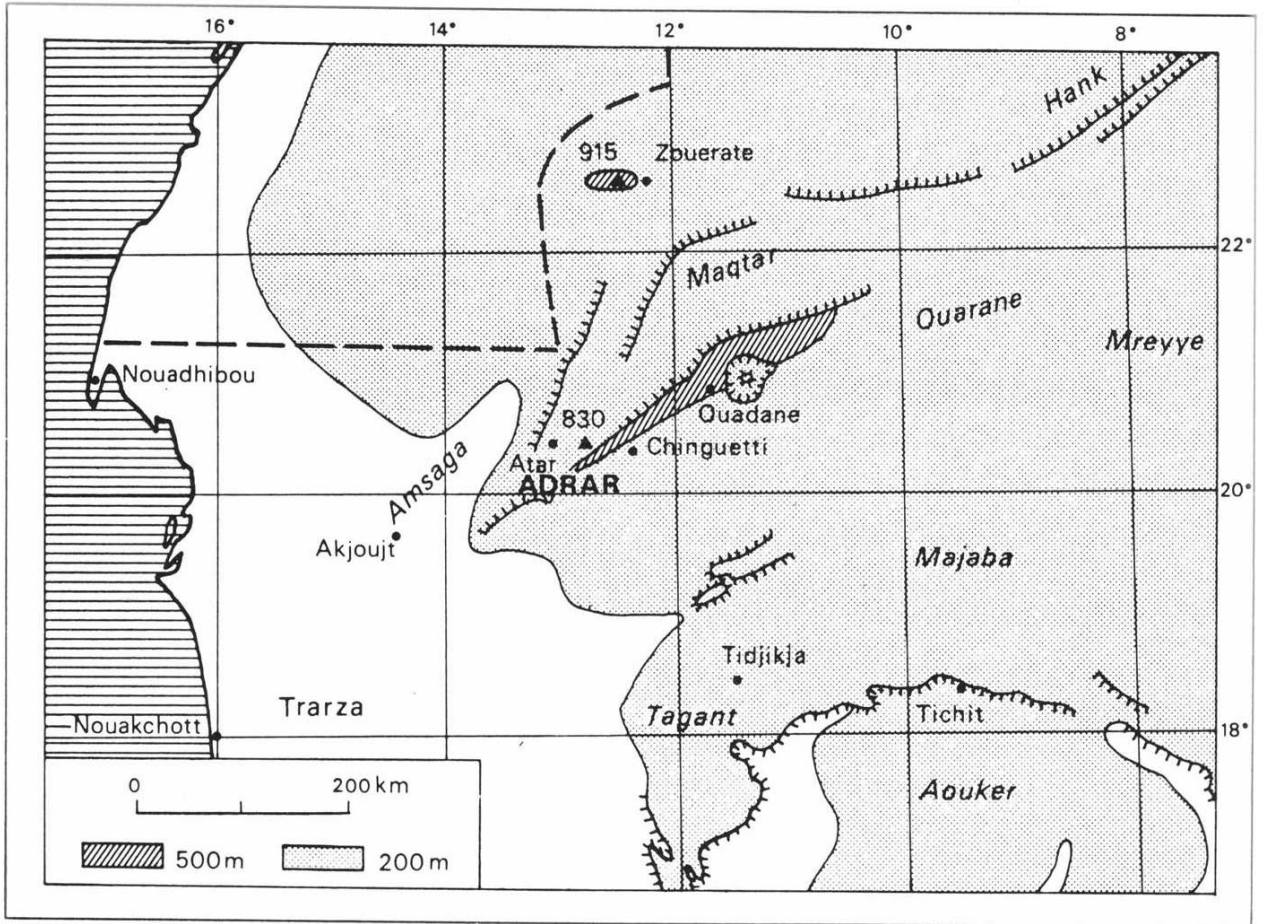

Occupé dès le Paléolithique inférieur (Acheuléen d'El Beyyed, de Ouadan, de la région d'Atar), l'Adrar connut aussi un peuplement important à l'Atérien (Oued Varichi, Tenyarada...) et surtout au Néolithique (vestiges nombreux autour d'Atar, au nord et au voisinage de Zouérate). Les populations néolithiques, sans avoir, semble-t-il, connu le développement quasi urbain de celles de la région de Tichit, plus au sud, subirent plus rapidement les méfaits de l'assèchement. Leurs descendants furent chassés par l'arrivée des "Equidiens", conducteurs de chars dont l'appartenance au stock paléoberbère ne fait guère de doute aujourd'hui.

On ne sait si les Bafours* (Bavur), auxquels les Maures attribuent la construction de très nombreux ksours aujourd'hui ruinés et sites diversement aménagés en bordure de falaise, sont les descendants des Néolithiques négroïdes ou des Paléoberbères avant leur islamisation. Certains auteurs voient en eux des populations blanches déjà islamisées mais peut-être kharedjites. Quant aux Gangara (Wangara), ce sont sûrement des populations noires qui occupaient le Tagant avant l'expansion almoravide du $\mathrm{XI}^{\mathrm{e}}$ siècle. Dans l'ensemble des sites bafours, R. Mauny a reconnu aussi bien des villages authentiquement néolithiques (Tentaïchot, Tinzak...) que des ksours ruinés d'époque médiévale (Tiftelle, Tin Labbe...) ou des habitats d'époque indéterminée dont beaucoup semblent postérieurs au $\mathrm{xVI}^{\mathrm{e}}$ siècle. Ces ruines révèlent, quel que soit leur âge, le recul des populations sédentaires devant le désert et les rezzous maures. Ainsi Azūgi, citadelle " almoravide », fut-elle occupée jusqu'au XviII siècle.

Les premières vagues berbères ont contribué à la fois au peuplement blanc et au développement de l'élevage tandis que les rares oasis de l'Adrar (Ouadane, Chinguetti) continuaient à être cultivées par des Noirs. Ces oasis, surtout Ouadane, ont entretenu des relations régulières avec les cités caravanières du Nord (Sijilmasa, Marrakech) et les vallées des fleuves, Sénégal et Niger, au sud. Cette importance du commerce explique le rôle prépondérant de Chinguetti et des palmeraies d'Atar et de Awjeft. 
5 L'islamisation des populations de l'Adrar fut l'œuvre des grandes tribus guerrières berbères, principalement des Lemtūna*, chez qui se forgea le mouvement almoravide* . L'Adrar était entièrement berbérophone et islamisé lorsque les Arabes Beni Ḥassān (ou Doui Hassān) firent leur apparition. Cette tribu du groupe Ma'quil était arrivée dans le sud du Maroc au XIII ${ }^{\mathrm{e}}$ siècle. Leur migration vers le sud, par infiltration de petits groupes, se fit surtout à partir du XVII ${ }^{\mathrm{e}}$ siècle et se poursuivit jusqu'à nos jours. Les Awled Bu Sba, d'origine marocaine, refoulés par les Regueibat, occupent l'Adrar, tandis que ces derniers pénètrent au cours des premières années du $\mathrm{xx}^{\mathrm{e}}$ siècle dans le Tagant et le Hodh.

$6 \mathrm{Au} \mathrm{XVIII}{ }^{\mathrm{e}}$ siècle se constitua dans l'Adrar un émirat à l'imitation de ceux établis dans le sud, au voisinage du fleuve Sénégal. Le fondateur en est 'At-man, un Arabe Hassan dont le commandement s'exerça de 1745 à 1785 ( ?). Ses successeurs, d'abord son frère Lgr' (le chauve) puis son fils Sīdī Aḥmed, s'appuyèrent sur trois tribus Hassān, les Awled 'Ammoni, les Awled Askar et les Awled Qaylan qui étaient, en fait, surtout les derniers, composés d'éléments d'origines diverses, en majorité arabe mais aussi zenaga (berbère). Au cours de la lutte qui opposa Sidi Aḥmed à son oncle, les Awled Qaylan profitèrent de leur rôle prépondérant pour imposer certaines règles de succession des émirs qui furent choisis dans la lignée d"Atman par une jema'a dans laquelle les Awled Qaylan étaient majoritaires («Réforme des Trois Mohammed )). L'émirat de l'Adrar étendit, au XIX ${ }^{\mathrm{e}}$ siècle, son influence vers l'est, entrant dans un long conflit avec les Kunta qui ne s'acheva qu'avec la conquête française au début du $x^{\mathrm{e}}$ siècle. Pendant toute la durée de l'émirat, les tribus Ḥassan continuaient à combattre pour leur propre compte, contribuant ainsi à l'arabisation de plus en plus marquée de l'Adrar.

7 Aujourd'hui, comme dans le reste de la Mauritanie, ces populations sont confondues sous l'appellation de Beyḍan (les « Blancs ») et forment une société très hiérarchisée à la tête de laquelle se situent les descendants des Arabes Beni Hassan et les familles maraboutiques, voire chérifiennes, bien que souvent d'origine berbère zenaga; les ksouriens, noirs, constituent la majorité de la population dont le total est estimé à 55000 personnes.

Minaret de Chinguetti, Šingeti (photo R. Mauny).

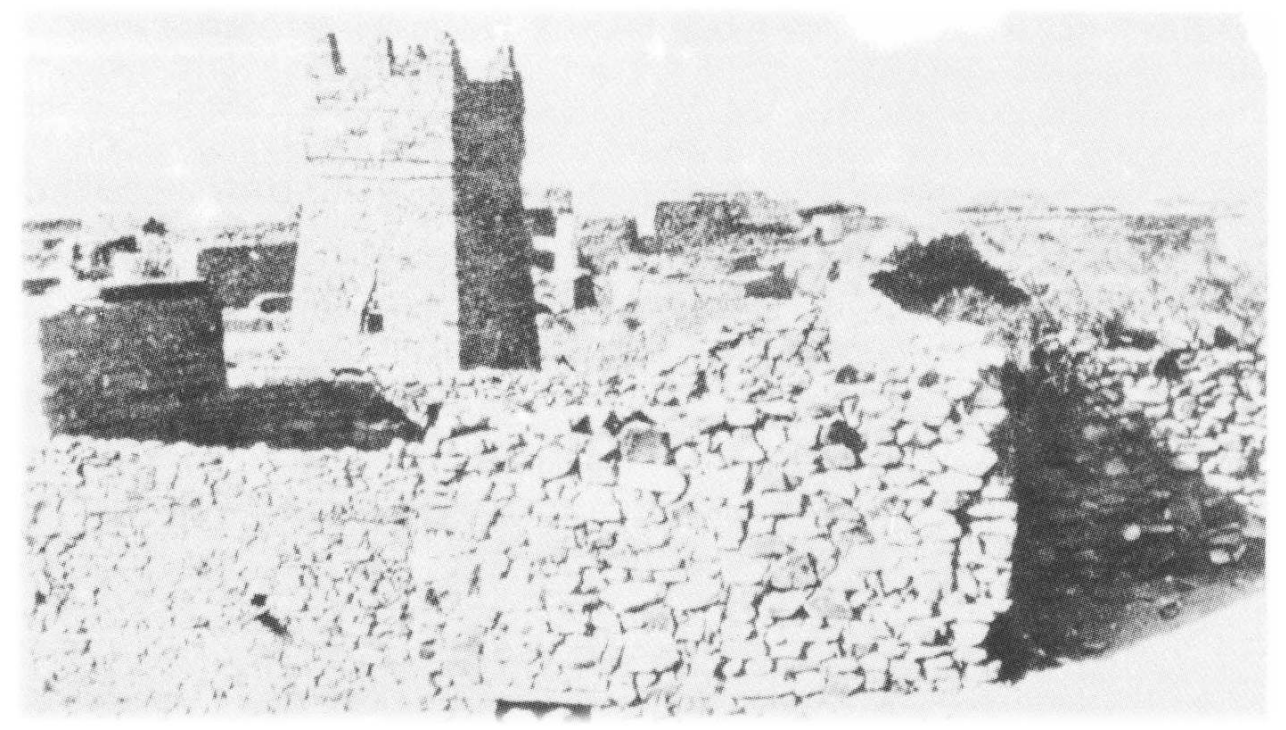




\section{BIBLIOGRAPHIE}

ABD EL WADDUD OTJD CHEIKH et SAISON B. Vie(s) et mort(s) de el imām al Hadrāmi. Autour de la postérité saharienne du mouvement almoravide. Table ronde « Les agents religieux islamiques en Afrique ", Paris 1983.

BONTE P. La constitution de l'émirat de l'Adrar : quelques hypothèses provisoires. Rev. de l'Occident musulman et de la Méditerranée, n. ${ }^{\circ} 32$, 1981, p. 37-51. - Tribus, factions et État. Les conflits de succession dans l'émirat de l'Adrar. Cahiers d'Études africaines 87-88, t. XXII, 1982, p. 489-516. BEYRIES J. Evolution sociale et culturelle des collectivités nomades de Mauritanie. Bulletin du Comité d'Étud. hist. et scient, de l'A.O.F., n. ${ }^{\circ}$ 4, oct.-déc. 1937, p. 465-481.

BORRICAND Lt.-Col. Le nomadisme en Mauritanie. Trav. de l'Instit. de Rech. Sahar., t. V, 1948, p. 81-94. CAPOT-REY R. Le Sahara français. P.U.F., Paris, 1953, p. 385-387.

DUBIE P. L'îlot berbérophone de Mauritanie. Bull, de l'Instit. franc. d'Afrique noire, t. 2, n. ${ }^{\circ}$ 3-4, 1940, p. 316-325.

JACQUES-MEUNIE D. Cités anciennes de Mauritanie. Klincksieck, 1961.

LERICHE A. Note sur les classes sociales et quelques tribus en Mauritanie. Bull, de l'Instit. franc, de l'Afrique noire, t. XVII, B, n. ${ }^{\circ} 1-2,1955$, p. 173-203. Marty P. Les tribus de Haute Mauritanie. Renseignements colon., 1915, p. 73, 82, 118-126, 136-145.

MAUNY R. Tableau géographique de l'Ouest africain au Moyen Age, d'après les sources écrites, la tradition et l'archéologie. IFAN Dakar, 1961.

MONOD TH. Sur quelques constuctions anciennes du Sahara occidental. Bull, de la Soc. de Géogr. et d'Archéol. d'Oran, t. 71, 1948, p. 23-52.

NICOLAS F. La langue berbère de Mauritanie. IFAN, Dakar, 1953.

VERNET R. La préhistoire de Mauritanie, état de la question. Thèse ronéo ; Paris, 1983.

Introduction à la Mauritanie. Ouvrage collectif. Edition CNRS, Paris, $1979 ; 421$ p.

\section{INDEX}

Mots-clés: Mauritanie, Géographie 